\title{
TECHNOLOGY DEVELOPMENT FOR IRON FISCHER-TROPSCH CATALYSIS
}

Contract No. DE-AC22-91PC94055

Quarterly Technical Progress Report No. 7

Covering the Period April 1, 1996 to June 30, 1996

\section{Prepared for}

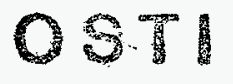

\author{
U.S. Department of Energy \\ Pittsburgh Energy Technology Center \\ PETC Project Manager: Richard E. Tischer \\ P. O. Box 10940 \\ Pittsburgh, PA 15236-0940
}

\author{
Submitted by \\ Project Manager: Burtron $\mathrm{H}$. Davis \\ University of Kentucky Research Foundation \\ Kinkead Hall \\ Lexington, KY 40506-0057
}

Date Revised and Accepted

August 7, 1996

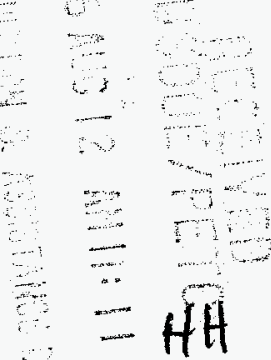

DISTRIBUTION OF THIS DOCUMENT IS IMU IMITED 


\section{DISCLAIMER}

This report was prepared as an account of work sponsored by an agency of the United States Government. Neither the United States Government nor any agency thereof, nor any of their employees, makes any warranty, express or implied, or assumes any legal liability or responsibility for the accuracy, completeness, or usefulness of any information, apparatus, product, or process disclosed, or represents that its use would not infringe privately owned rights. Reference herein to any specific commercial product, process, or service by trade name, trademark, manufac: turer, or otherwise does not necessarily constitute or imply its endorsement, recommendation, or favoring by the United States Government or any agency thereof. The views and opinions of authors expressed herein do not necessarily state or reflect those of the United States Government or any agency thereof. 


\section{DISCLAIMER}

Portions of this document may be illegible in electronic image products. Images are produced from the best available original document. 


\section{Contract Objectives}

The objective of this research project is to develop the technology for the production of physically robust iron-based Fischer-Tropsch catalysts that have suitable activity, selectivity and stability to be used in the slurry phase synthesis reactor development. The catalysts that are developed shall be suitable for testing in the Advanced Fuels Development Facility at LaPorte, Texas, to produce either low- or high-alpha product distributions. Previous work by the offeror has produced a catalyst formulation that is 1.5 times as active as the "standard-catalyst" developed by German workers for slurry phase synthesis. The proposed work will optimize the catalyst composition and pretreatment operation for this low-alpha catalyst. In parallel, work will be conducted to design a high-alpha iron catalyst this is suitable for slurry phase synthesis. Studies will be conducted to define the chemical phases present at various stages of the pretreatment and synthesis stages and to define the course of these changes. The oxidation/reduction cycles that are anticipated to occur in large, commercial reactors will be studied at the laboratory scale. Catalyst performance will be determined for catalysts synthesized in this program for activity, selectivity and aging characteristics.

The research is divided into four major topical areas: (a) catalyst preparation and characterization, (b) product characterization, (c) reactor operations, and (d) data assessment.

To accomplish the objectives of the project, these topics have been organized into the following technical tasks:

a. Task 1.0 Development of Optimum Promoter Levels for Low- and High-Alpha Catalysts 
1.1 Determine Optimized Synthesis Procedure for High-Alpha IronBased Fischer-Tropsch Catalysts

- Role of precursor particle size on activity.

- Role of $\mathrm{Cu}$ in precipitated catalysts.

- Define attrition resistance.

1.2 Prepare Catalysts that can be Used to Determine the Role of Promoters for Low- and High-Alpha Catalysts

- Define optimum $\mathrm{SiO}_{2}$.

- Define optimum $\mathrm{Al}_{2} \mathrm{O}_{3}$.

1.3 Prepare Catalysts that can be Used to Quantify the Role of K on Product Selectivity in both Low- and High-Alpha Catalysts.

1.4 Complete the Optimization of the Two Best Low-Alpha, Iron-Based Fischer-Tropsch Catalysts Developed during the Previous Contract.

b. Task 2.0 Definition of Preferred Pretreatment for both Low- and High-Alpha Fischer-Tropsch Catalysts.

2.1 Determine the Role of $\mathrm{Cu}$ in the Activation of Precipitated Lowand High-Alpha, Iron-Based Fischer-Tropsch Catalysts.

2.2 Determine the Effect of $\mathrm{K}$ Content on Activation Procedures and Determine if the Method of Addition has any Effect on Catalyst Activity and Life.

2.3 Determine the Physical and Chemical Changes that Occur during Catalyst Pretreatment and Use and Determine how these Changes Effect the Strength of the Catalysts. 
2.4 Evaluate the Effect of Carbon Deposition during Catalyst Activation on Activity, Selectivity and Aging Characteristics.
c. Task 3.0 Catalyst Structure and Characterization.
d. Task 4.0 Catalyst Testing.

4.1 Verify the Quality of Data Obtained from the CSTR's.

4.2 Measure Catalyst Performance.

4.3 Determine the Stable Phases that Exist during Synthesis at Low and High CO Conversion Levels.

4.4 Obtain Data on the Rates Involved in the Interconversion of Iron Oxide and Iron Carbide.

\section{e. Task 5.0 Reports.}

\section{Summary of Activities}

The rates of deactivation of iron-based Fischer-Tropsch catalysts are examined for correlations with partial pressures and to determine the cause(s) of deactivation. There is no correlation between either the partial pressure of water or the partial pressure ratio $\mathrm{P}_{\mathrm{CO}} / \mathrm{P}^{2}{ }_{\mathrm{H} 2}$ and the deactivation rates. Transformation of the catalyst phase to iron oxide can be ruled out as causing deactivation. Sintering or carbon deposits cannot be conclusively identified from the results.

The first run using the new BCSR system was completed. The run lasted for 233 hours (synthesis time) with no operational problems, and was terminated to increase the catalyst loading. The catalyst (RLS 4-4 Si/150 cyclone) loading was $10 \%$. The catalyst was pretreated in $\mathrm{CO}(1 \mathrm{~atm})$ at $270^{\circ} \mathrm{C}$ using a gas space velocity of 2.9 SL/hr-g Fe, a superficial gas velocity of $10 \mathrm{~cm} / \mathrm{sec}$, for 21 hours. During the synthesis period, 3 space velocities (12, 6 and $4 \mathrm{SL} / \mathrm{hr}-\mathrm{g} \mathrm{Fe})$ were investigated. Conversions 
$\left(\mathrm{CO}+\mathrm{H}_{2}\right)$ of $28 \%, 35 \%$ and $43 \%$, respectively, were obtained using the different space velocities. Mass balances were all $98 \%$ or better during the entire run. The K-ray detector, which measures the density of the reactor contents, indicated that the catalyst was suspended uniformly throughout the reactor at the 3 space velocities studied. The catalyst recycle system worked very well during the entire run. No visible catalyst was observed in the wax product. The Fe content of the wax samples was $\leq 20 \mathrm{ppm}$.

\section{Status, Accomplishments, Results and Discussion}

A.0. - Task 1.0. Development of Optimum Promoter Levels for Low- and High-

\section{Alpha Catalysts}

The goal of this task is to identify and optimize procedure for the preparation of iron-based catalysts that combine high activity selectivity and life with physical robustness. Each of the subtasks address an area of considerable uncertainty in the synthesis of catalysts.

\section{A.1. Determine Optimized Synthesis Procedure for High-Alpha Iron-Based}

Catalysts

No scheduled or further activity to report.

A.2. Prepare Catalysts that can be Used to Determine the Role of Promoters for Low- and High-Alpha Catalysts

No scheduled or further activity to report.

A.3. Prepare Catalysts that can be Used to Quantify the Role of K on Product

Selectivity for both High- and Low-Alpha Catalysts

Low-alpha catalyst work has been successfully completed. 
A.4. Complete the Optimization of Two Best Low-Alpha, Iron-Based Catalysts Developed During the Previous Contract

Completed.

\section{A.5. Schedule of Activities for Next Quarter}

- Begin optimization of the robust alumina supported catalyst to increase conversion, selectivity and production.

B.0. - Task 2.0. Definition of Preferred Pretreatment for Both Low- and HighAlpha Catalysts

The goals of this task are to define the preferred treatment, to define the role of $\mathrm{Cu}$ and $\mathrm{K}$ during the pretreatment on activity and selectivity and to define the chemical and physical changes which occur during the preferred pretreatment. The subtasks address each of these goals.

B.1. Role of $\mathrm{Cu}$ in the Activation of Precipitated Low- and High-Alpha, Iron Based Fischer-Tropsch Catalysts

This task has been successfully completed for both high and low alpha catalysts.

B.2. Determine the Effect of K Content on Activation Procedures and

Determinate if the Method of Addition has any Effect on Catalyst Activity and Life.

The work on the method of addition has been completed.

B.3. Physical and Chemical Changes that Occur During Pretreatment and Use No scheduled or further activity to report.

\section{B.4. Effect of Carbon Deposition}

No scheduled or further activity to report. 


\section{B.5. Schedule of Activities for Next Quarter}

Continue to determine effectiveness of $\mathrm{Ba}$ and $\mathrm{Zn}$ as promoters. These potential promoters should, to a first approximation mimic the alkali promoters we have been studying.

\section{C.0. - Task 3.0. Catalyst Structure and Characterization}

The goal of this task is to provide basic analyses (surface area, XRD) of all catalyst prepared and to provide additional techniques as required (Mössbauer, SEM, XPS, etc.) to answer specific questions or to provide basic required characterization data for the catalysts.

\section{C.1. Schedule of Activities for Next Quarter}

Continue to provide the characterization data as required.

\section{D.0. - Task 4.0. Catalyst Testing}

The goals of this task are to operate the eight CSTR reactors, measure catalyst performance, determine the stable phases that exist during synthesis at low and high conversions and to determine the rates of interconversion of iron oxide and carbide.

\section{D.1. Verify the Quality of Data Obtained from the CSTRs.}

This task is now successfully completed.

\section{D.2. Measure Catalyst Performance}

\section{D.2.1. Catalyst Deactivation}

The Fischer-Tropsch synthesis (FTS) process converts synthesis gas to liquid fuels, waxes and hydrocarbon gases. The iron-based catalysts lose activity with time on stream (TOS) during the FTS. The possible causes of catalyst deactivation include: (i) phase transformations of the catalyst surface to the oxide, (ii) build-up of carbon/coke deposits, and, (iii) sintering of the catalyst particles. 
A higher partial pressure of water leads to a more oxidizing environment and the formation of iron oxide. Water is also known to increase the carbon build-up on the catalyst and the rate of sintering. Since the WGS occurs mainly (though not exclusively) on the oxide phase, it has been postulated that an increase in the ratio of the rate of the FTS ( $\left.r_{\text {FTS }}\right)$ to the rate of the WGS $\left(r_{\text {WGS }}\right)$ during deactivation indicates the formation of iron oxide. In a previous study, the carbon deposition rate has been shown to be proportional to the value of the partial pressure ratio $\mathrm{P}_{\mathrm{CO}} / \mathrm{P}_{\mathrm{H} 2}^{2}$.

In this study we have investigated the deactivation of several iron-based catalysts during the FTS. An attempt is made to establish whether the deactivation rates and causes of activity decline can be related to the above factors.

Four precipitated iron-based catalysts are used in this study and are designated in terms of the atomic ratios as: $100 \mathrm{Fe}, 100 \mathrm{Fe} / 3.6 \mathrm{Si}, 100 \mathrm{Fe} / 0.71 \mathrm{~K}$, $100 \mathrm{Fe} / 3.6 \mathrm{Si} / 0.71 \mathrm{~K}$. The iron catalysts are prepared by continuous precipitation from iron (III) nitrate and ammonium hydroxide. For silica containing catalyst a colloidal suspension of tetraethyl ortho silicate in water is mixed with iron (III) nitrate solution prior to precipitation with ammonium hydroxide. Potassium is added to the catalysts in the form of potassium tertiary butoxide during the loading of the FTS reactor.

A 1 -liter stirred tank reactor is used for the FTS. A $20 \mathrm{wt} . \%$ (catalyst) slurry in the $\mathrm{C}_{30}$ oil was used to start the run. The FTS reaction conditions over all the catalysts are a temperature of $270^{\circ} \mathrm{C}$, a pressure of $175 \mathrm{psig}$, an $\mathrm{H}_{2} / \mathrm{CO}$ ratio of 0.7 and a syngas space velocity of $3.1 \mathrm{NL} / \mathrm{hr}-\mathrm{gFe}$. Pretreatment of the catalyst is carried out using pure $\mathrm{CO}$ at reaction conditions and a flow rate of $2 \mathrm{NL} / \mathrm{hr}-\mathrm{gFe}$ for 24 hours. Conversion data are obtained daily over each of the catalysts for TOS of up to 150 to 450 hours. Small quantities of the catalysts $(0.1$ to $0.2 \mathrm{~g}$ out of a total of $70 \mathrm{~g})$ are 
removed from the reactor just after pretreatment and at various TOS. After extraction with xylene, BET surface areas and amounts of carbon (by oxidation in air) are measured for the catalyst samples collected.

Synthesis gas conversions for the four catalysts studied are shown in Figure 1. There is an initial period of an increase in activity of between 1 to 2 days for each catalyst. The synthesis gas conversions after this initial period for the catalysts range between 75 to $88 \%$. The catalyst containing both silica and potassium show a relatively low and constant rate of deactivation with TOS. All the other catalysts, however, show much larger rates of deactivation. Further, the deactivation rates appear to accelerate with TOS for these catalysts. The rate of deactivation increases in the order $100 \mathrm{Fe} / 0.71 \mathrm{~K}>100 \mathrm{Fe}>100 \mathrm{Fe} / 3.6 \mathrm{Si}>100 \mathrm{Fe} / 3.6 \mathrm{Si} / 0.71 \mathrm{~K}$.

Sintering has been postulated as a possible cause of deactivation for ironbased FTS catalysts. The results for the catalysts studied, however, indicate an increase in surface area with TOS and deactivation as shown in Table 1. Such increases in surface areas are possible if high-area carbon is deposited on the catalyst surface. The amount of carbon on the catalysts does appear to increase with reaction time as shown in Table 1 in conformity with the above reasoning. However, the carbon amounts must be viewed with caution as they may also arise from iron carbides. The presence of carbides in the all the catalysts has been identified by Xray diffraction studies. Though there is an increase in the amounts of carbon with TOS there does not appear to be any correlation of these with the deactivation rates of the various catalysts. For instance, the catalyst with the lowest deactivation rate (100Fe/3.6Si/0.71K) has comparable if not more carbon deposits as the other catalysts. 
Since water has been implicated in increasing all three of the catalyst deactivation mechanisms, it is instructive to compare the water partial pressure with TOS for each of the catalysts. Two distinctly different trends are evident as shown in Figure 2. The catalysts without potassium have significantly higher partial pressures of water than potassium containing catalysts. Further, the partial pressure of water shows a rapid increase followed by a decrease with TOS over the catalysts without potassium. In contrast, the partial pressure of water shows only a gradual decrease with TOS over the potassium promoted catalysts.

There does not appear to be a correlation between the value of the partial pressure of water vapor in the reactor and the catalyst deactivation rates. For instance, the catalyst with the highest deactivation rate $(100 \mathrm{Fe} / 0.71 \mathrm{~K})$ has the lowest value of the water partial pressure. Also, the water partial pressure decreases at high times on stream for the catalysts without potassium whereas the deactivation rate increases for these catalysts at high TOS.

The ratio of the FTS to the WGS reaction rate (Figure 3) appears to increase rapidly at large TOS for the catalysts without potassium. This is exactly opposite to that expected if the catalyst is transformed to iron oxide. For the potassium containing catalysts, the value of the reaction rate ratio remains practically constant with TOS. If it is true that the formation of the oxide leads to a decrease in the reaction rate ratio then the above results indicate the absence of oxide formation.

Figure 4 shows the variation of the partial pressure ratio, $\mathrm{P}_{\mathrm{CO}} / \mathrm{P}^{2}{ }_{\mathrm{H} 2}$, with TOS for the catalysts studied. The catalysts without potassium exhibit both a higher initial value of this partial pressure ratio as well as an increase of this ratio with TOS. The value of the partial pressure ratio increases gradually for the catalyst containing both 
potassium and silicon but at a somewhat faster rate for the catalyst without silicon but with potassium. There is no clear correlation between the value of this ratio and the deactivation rates of the various catalysts. The catalyst with the highest deactivation rate $(100 \mathrm{Fe} / 0.71 \mathrm{~K})$ exhibits low values of the partial pressure ratio.

The rates of catalyst deactivation do not correlate with either the partial pressure of water or the partial pressure ratio $\mathrm{P}_{\mathrm{CO}} / \mathrm{P}_{\mathrm{H} 2}^{2}$. Since the ratio of the reaction rate of FTS to WGS either remains constant or increases with TOS, transformation of the catalytic phase to iron oxide can be ruled out as the only cause of deactivation. Surface areas of the spent catalyst samples increase with TOS and thus are not suitable as a measure of the presence/absence of sintering. Though the spent catalyst samples contain carbon, oxidation of the samples in air does not distinguish between carbide and coke. Hence, coking of the catalysts cannot be definitively identified as a cause of deactivation.

\section{D.2.2. Slurry Bubble Column Reactor}

Modification of the CAER direct liquefaction 6'X2" reactor and process control systems to convert it to a slurry bubble column reactor for FTS was completed. This entailed the replacement of all tubing and a thorough cleaning of the reactor and other non-replaceable systems to ensure that the catalyst would not be poisoned by trace amounts of sulfur in the system. The process and reactor systems were successfully treated prior to an actual run in June. One of the modifications that was tested in the first run of S.B.C.R. was the cyclone separation system that was developed for the CSTR system. A process diagram of the CAER, S.B.C.R. is shown in Figure 5.

The catalyst, RLS $4.4 \mathrm{Si} / 150$ cyclone $\left(56.0 \mathrm{wt} \% \mathrm{Fe}, 1.43 \% \mathrm{Si}, 0.49 \% \mathrm{~K} ; 113 \mathrm{~m}^{2} / \mathrm{g}\right.$ ) was chosen as the catalyst for the initial run (Run 501). A 10 wt\% slurry of the catalyst 
( $210 \mathrm{~g}$ calcined catalyst, $1900 \mathrm{~g} \mathrm{C}_{30}$ oil) was used. The catalyst was pretreated using $\mathrm{CO}(\mathrm{GHSV}=2.9 \mathrm{SL} / \mathrm{hr}-\mathrm{g} \mathrm{Fe} ; \mathrm{Ug}=10 \mathrm{~cm} / \mathrm{sec})$ at $1 \mathrm{~atm}$ and $270^{\circ} \mathrm{C}$ for 21 hours.

FTS was started after pretreatment using a reactor temperature of $270^{\circ} \mathrm{C}$, 170psig reactor pressure, and on $\mathrm{H}_{2} / \mathrm{CO}=0.7$. Three gas hourly space velocities, 12SL/hr-g Fe $(\mathrm{Ug}=3.0 \mathrm{~cm} / \mathrm{sec}) 6 \mathrm{SL} / \mathrm{hr}-\mathrm{g} \mathrm{Fe}(\mathrm{Ug}=1.5 \mathrm{~cm} / \mathrm{sec})$, and $4.0 \mathrm{SL} / \mathrm{hr}-\mathrm{g} \mathrm{Fe}$ $(\mathrm{Ug}=1.0 \mathrm{~cm} / \mathrm{sec})$, were studied during the 233 hour run. K-ray measurements, which determine the density distribution of the materials within the reactor, were taken at each space velocity to determine if the catalyst was uniformly distributed down the reactor.

The conversion data obtained during the entire run are shown in Figure 6. Using these synthesis conditions, the conversions were slightly lower than expected, based on the data obtained in CSTR runs. All mass balances obtained during the run were all greater than $98 \%$ (Figure 7). The data obtained from the K-ray (Figure 8) show that the catalyst was uniformly distributed in the reactor using the three space velocities studied. Analysis of the products are in progress.

During the 233 hours of operation, there were no processing problems. The only potential problem occurred at run hour 177 when the entire building lost power for 1 hour. However, as shown in Figure 6, the loss of power had little impact on the process. The newly designed cyclone separator system installed on top of the BSCR also worked extremely well. The wax obtained from the process showed no visible signs of any catalyst. Analysis of the wax product for Fe content is in progress. At the end of the run, all gas flows were shut off to determine how rapidly the catalyst would settle. Figure 9 shows the data obtained from the K-ray. The density data show that the catalyst settles slowly without gas flows. 
D.3. Determine Stable Phases that Exist During Synthesis at High and Low CO

Conversion Levels

We have completed runs using an unpromoted $\mathrm{Fe}$ and a $\mathrm{K}$ promoted $\mathrm{Fe}$ catalyst which will provide samples for the analysis of the stable phases. Samples have been submitted.

D.4. Obtain Data on Rates Involved in the Interconversion of Iron Oxide and

\section{Carbide}

No scheduled or additional activity to report.

D.5. Schedule of Activities for Next Quarter

- Continue the evaluation of the wax/catalyst separation.

- Continue to make additional supported Fe catalysts and test their activity, selectivity and productivity rate.

- Make an addition run in the CAER BSCR with a $20 \%$ catalyst loading.

- We will continue to study the deactivation of the catalysts to determine if this deactivation effect is general or catalyst specific. 


\begin{tabular}{||c|c|c|c|c|c|c|c|c||}
\hline \multicolumn{10}{|c|}{ Table 1 } \\
Surface Areas (S.A.) and Carbon Contents or Catalysts \\
with Time-on-Stream (TOS) \\
\hline $\begin{array}{c}\text { TOS } \\
(\mathrm{h})\end{array}$ & $\begin{array}{c}\text { S.A. } \\
\left(\mathrm{m}^{2} \mathrm{~g}^{-1}\right)\end{array}$ & $\begin{array}{c}\mathrm{C} \\
(\mathrm{wt} . \%)\end{array}$ & $\begin{array}{c}\text { TOS } \\
(\mathrm{h})\end{array}$ & $\begin{array}{c}\text { S.A. } \\
\left(\mathrm{m}^{2} \mathrm{~g}^{-1}\right)\end{array}$ & $\begin{array}{c}\text { C } \\
(\mathrm{wt} . \%)\end{array}$ & $\begin{array}{c}\text { TOS } \\
(\mathrm{h})\end{array}$ & $\begin{array}{c}\text { S.A. } \\
\left(\mathrm{m}^{2} \mathrm{~g}^{-1}\right)\end{array}$ & $\begin{array}{c}\text { C } \\
(\mathrm{wt} . \%)\end{array}$ \\
\hline 0 & 32 & 11.2 & 0 & 29 & 10.9 & 0 & 70 & 6.4 \\
\hline 72 & 31 & & 4 & 31 & 14.6 & 4 & 77 & 12.4 \\
\hline 337 & 44 & 17.8 & 26 & 20 & & 50 & 84 & 14.6 \\
\hline & & & 146 & 49 & 31.2 & 72 & 73 & 15.8 \\
\hline & & & & & & 148 & 77 & \\
\hline & & & & & & 461 & 87 & 29.7 \\
\hline
\end{tabular}

\begin{tabular}{|c|c|c|}
\hline \multicolumn{3}{|c|}{ Table 2 } \\
Fe Content of the Wax Products \\
\hline $\begin{array}{c}\text { Sample Run Hour } \\
\text { (hr) }\end{array}$ & $\begin{array}{c}\text { Space Velocity } \\
\text { (SL/hr-g Fe) }\end{array}$ & Fe (ppm) \\
\hline 44.5 & 12 & 22 \\
\hline 117 & 6 & $<10$ \\
\hline 161 & 4 & $<10$ \\
\hline 223 & 4 & $<10$ \\
\hline
\end{tabular}




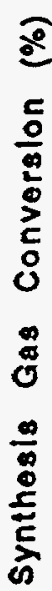

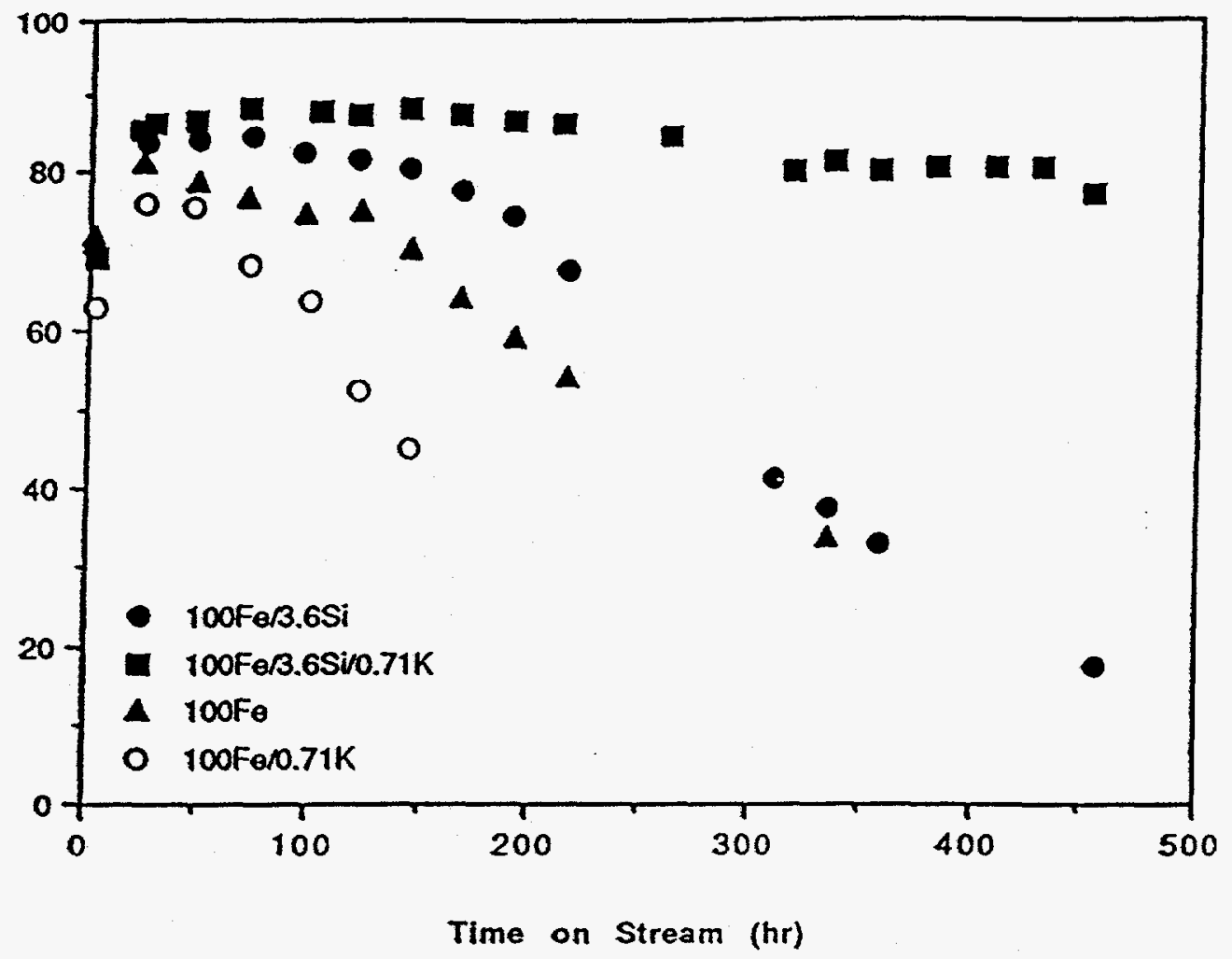

Figure 1. Conversion of Synthesis Gas with Time on Stream

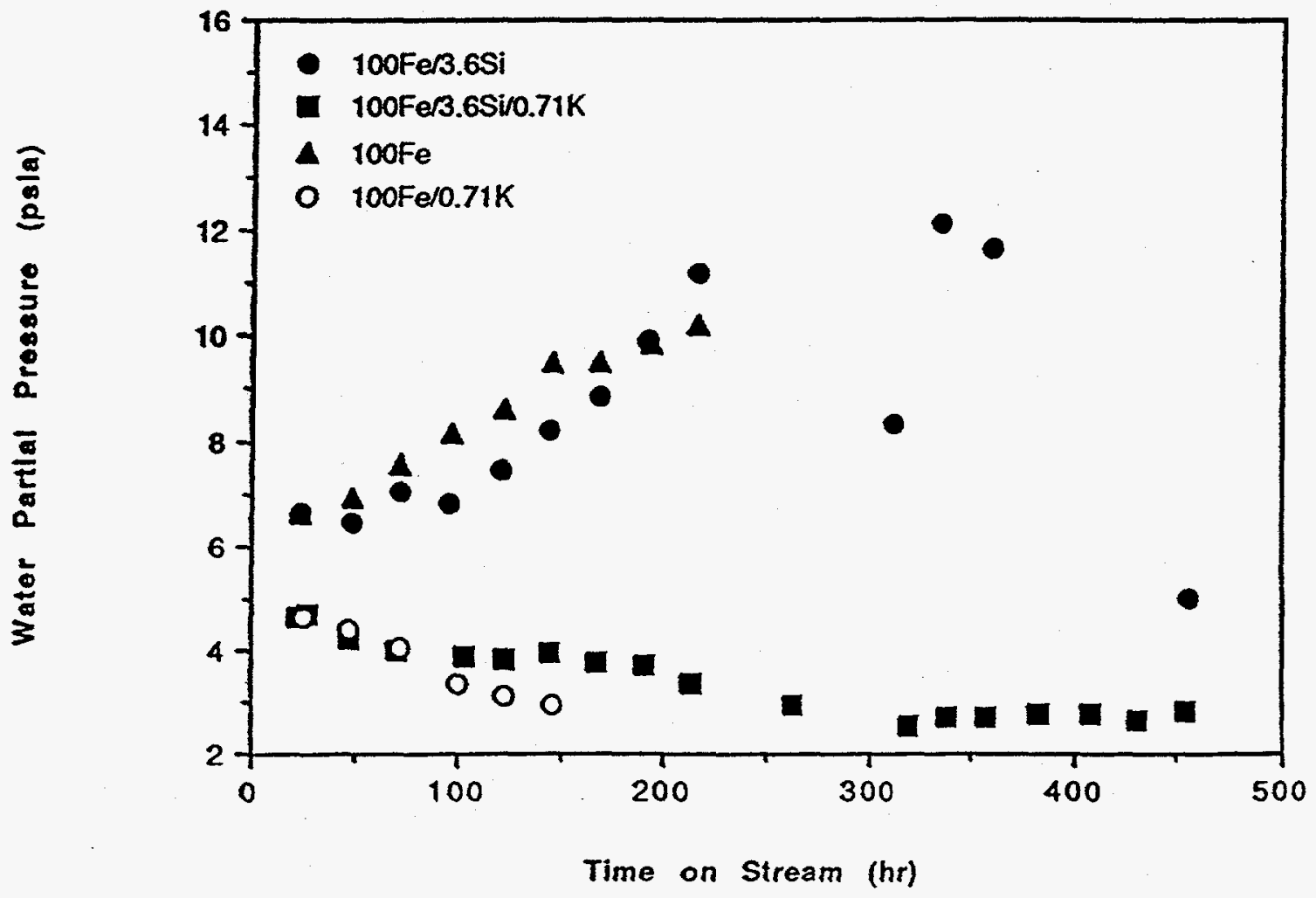

Figure 2. Water partial pressures with time on stream 


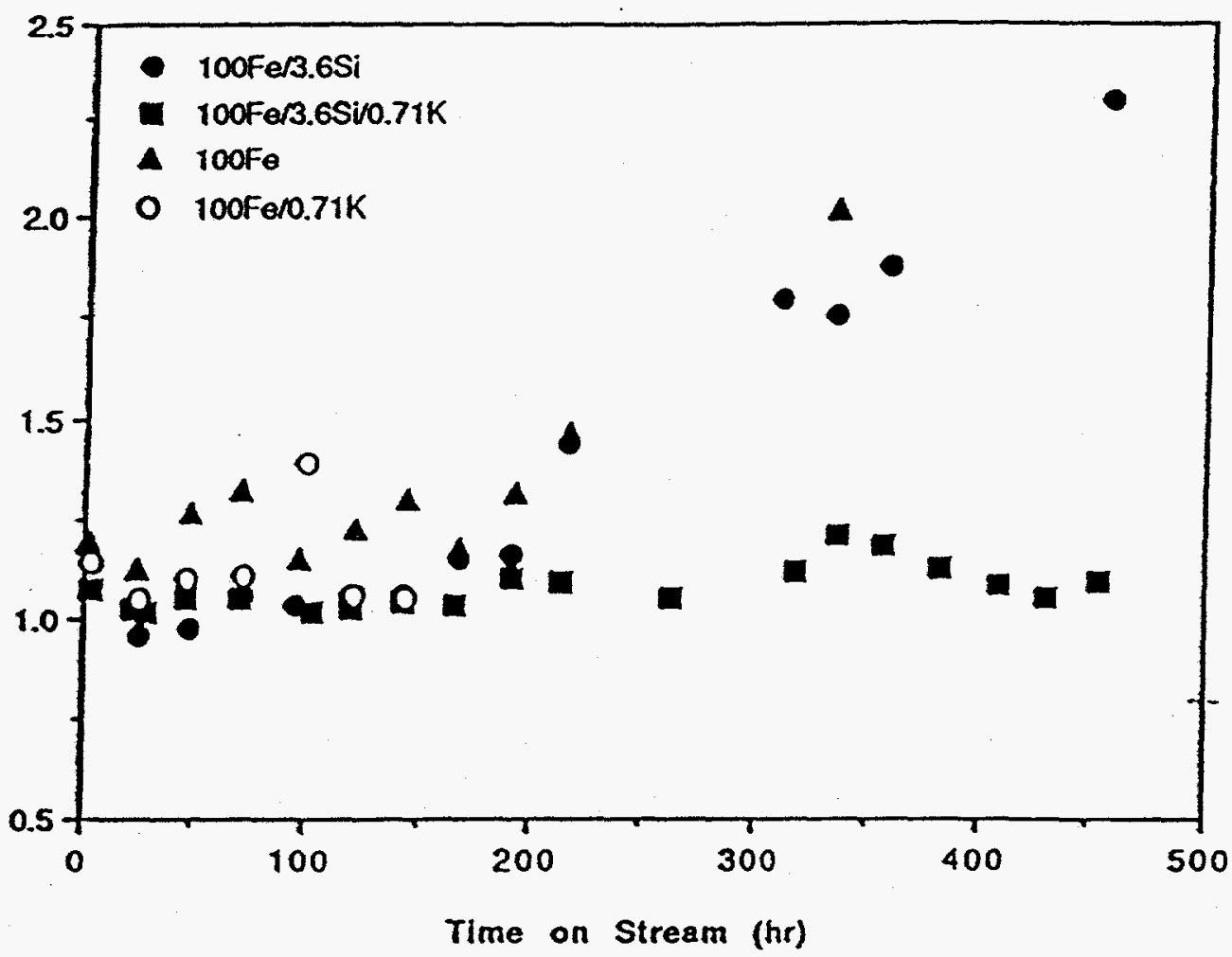

Figure 3. Ratio of the Reaction Rates of the Fischer-Tropsch to the Water Gas Shift

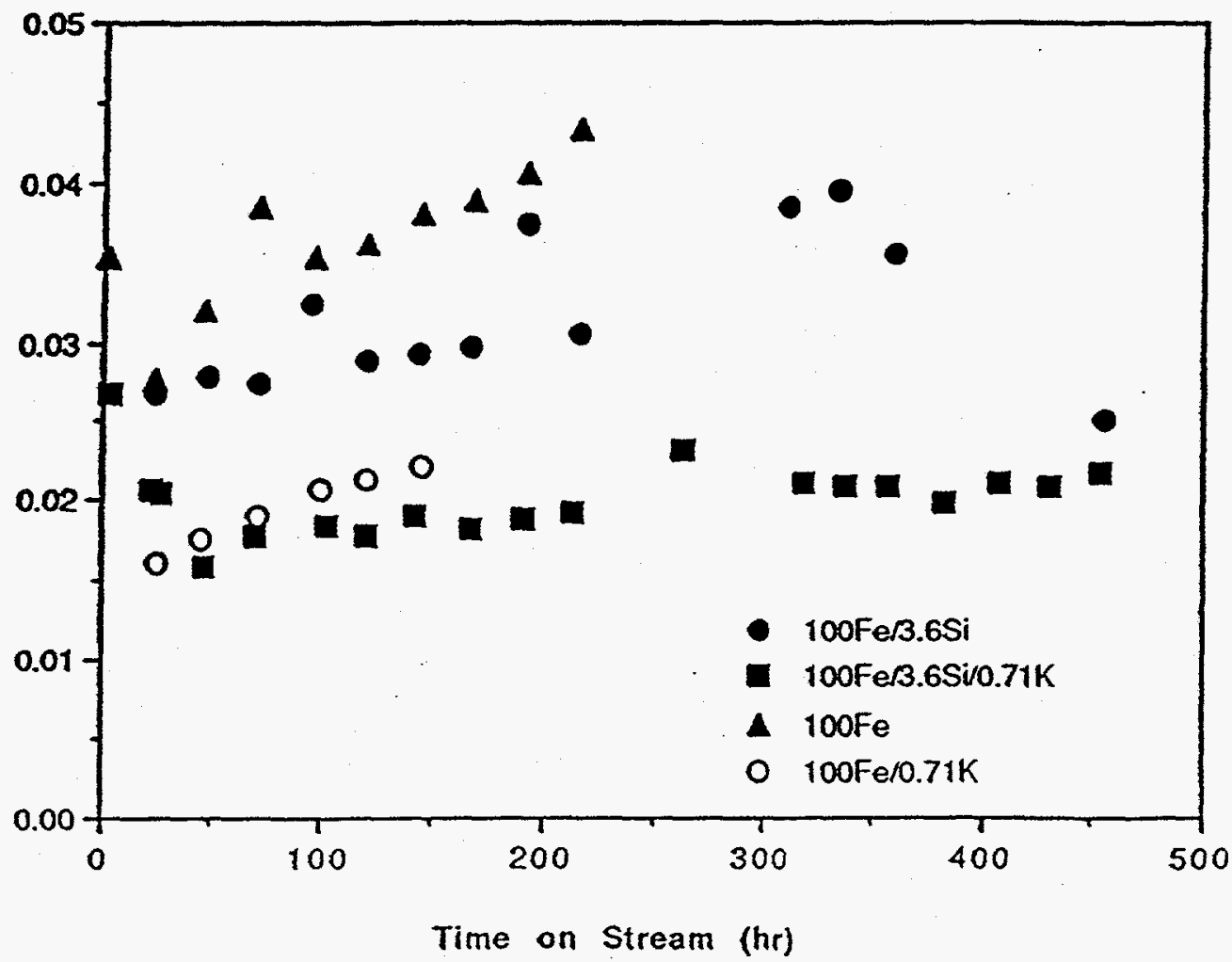

Figure 4. Values of the partial pressure ratio with time on stream 
Figure 5. Process diagram of the CAER SBCR.

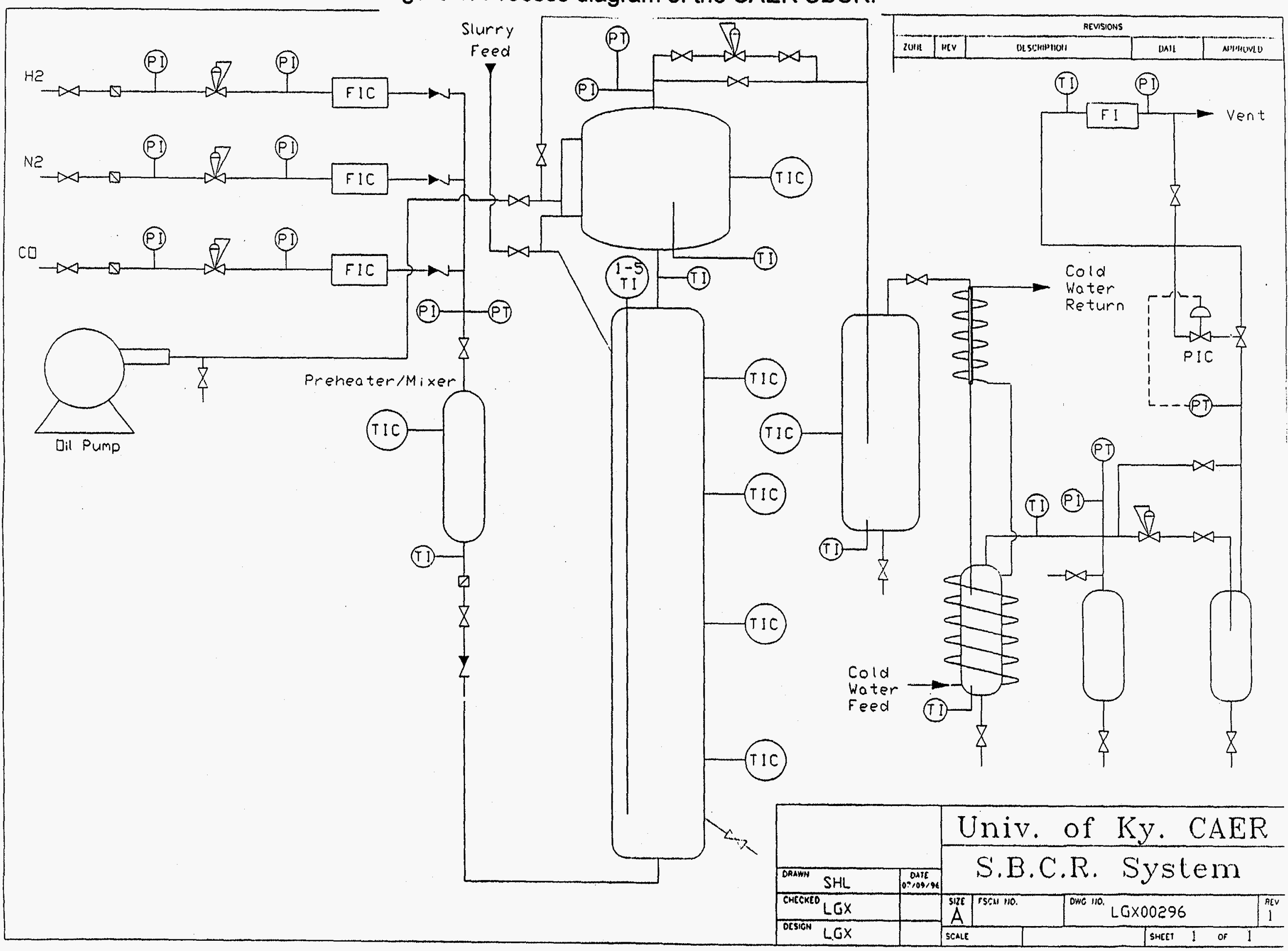


Figure 6.

Conversion vs Syn. time (S.B.C.R. 501)

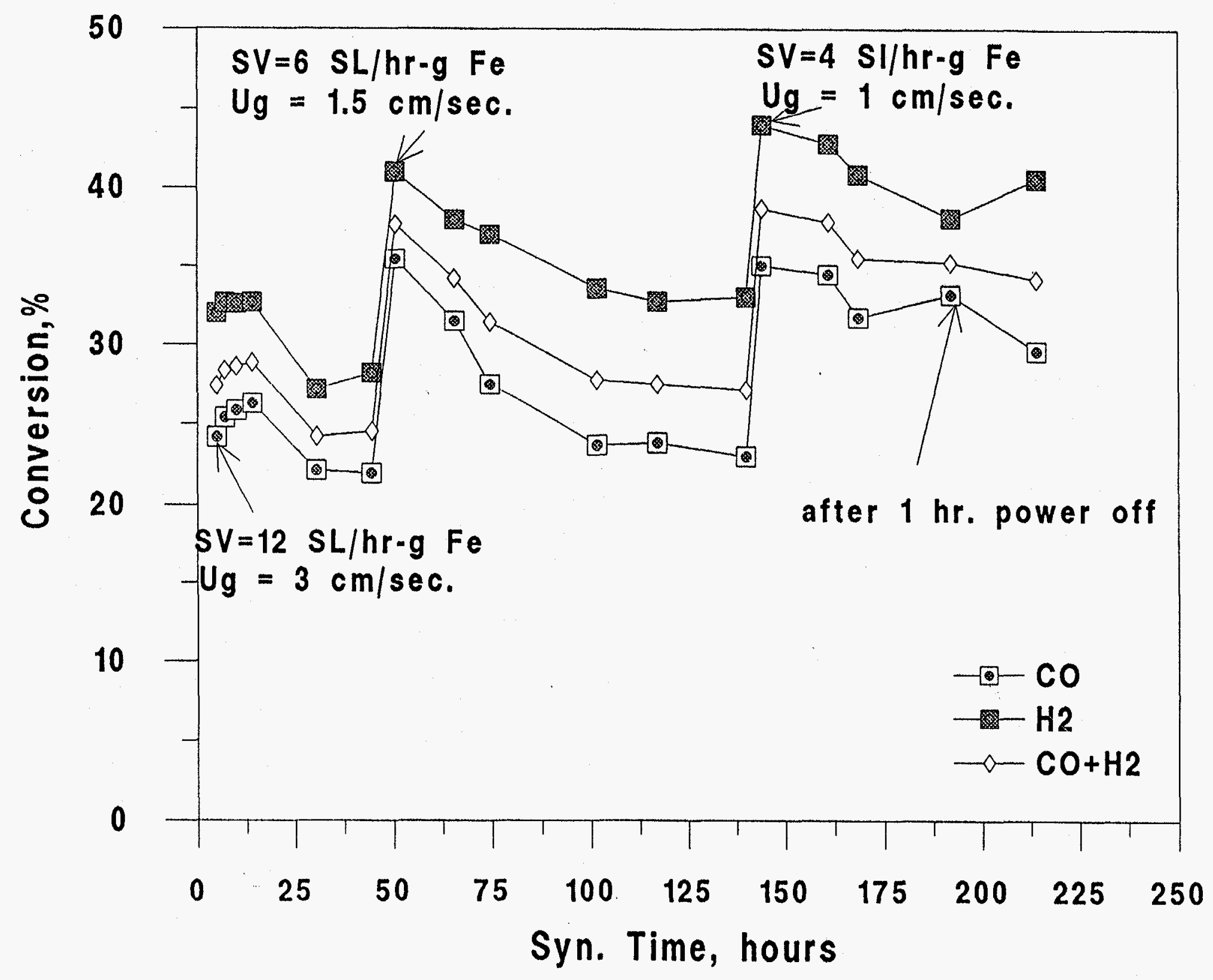




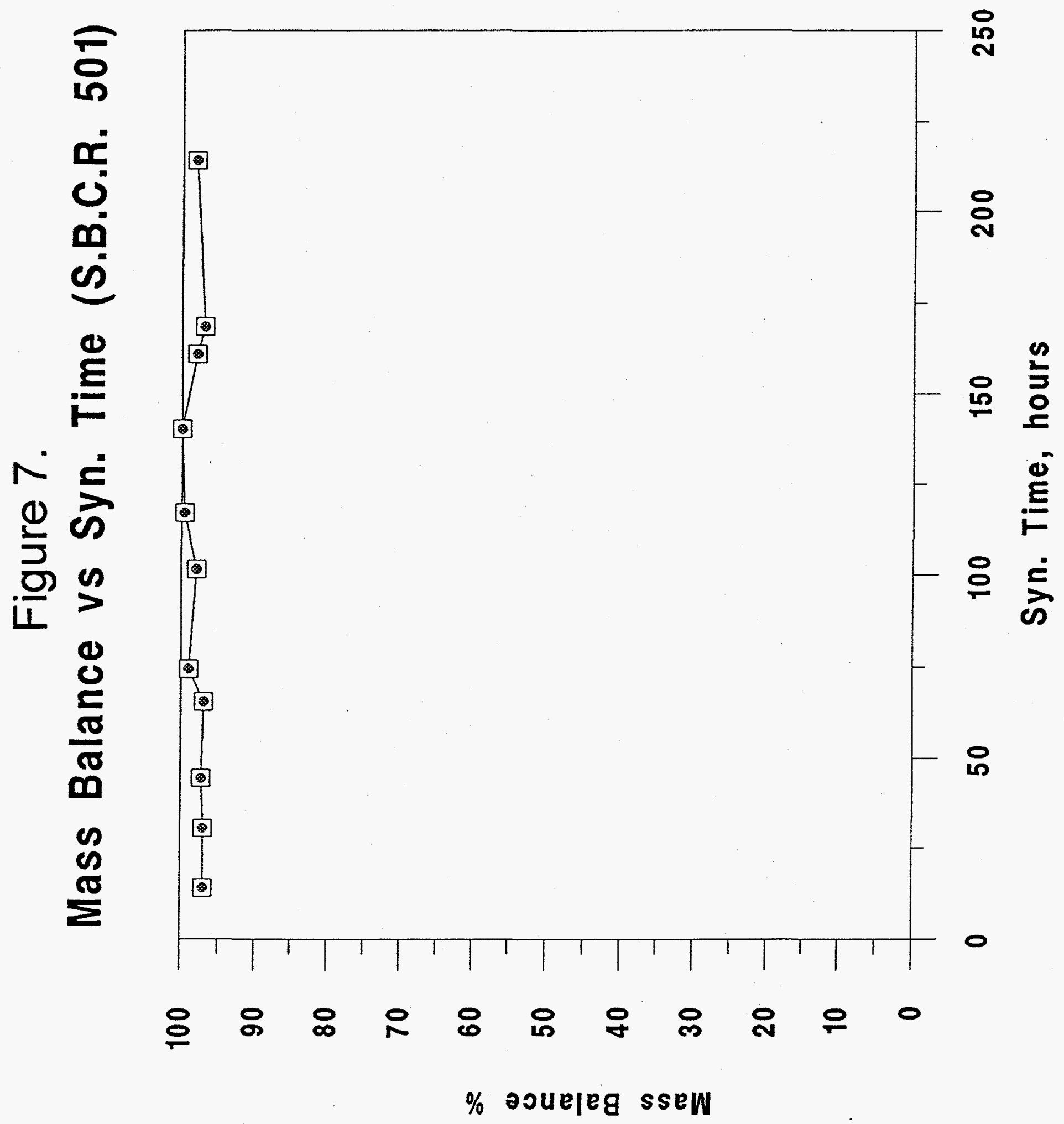




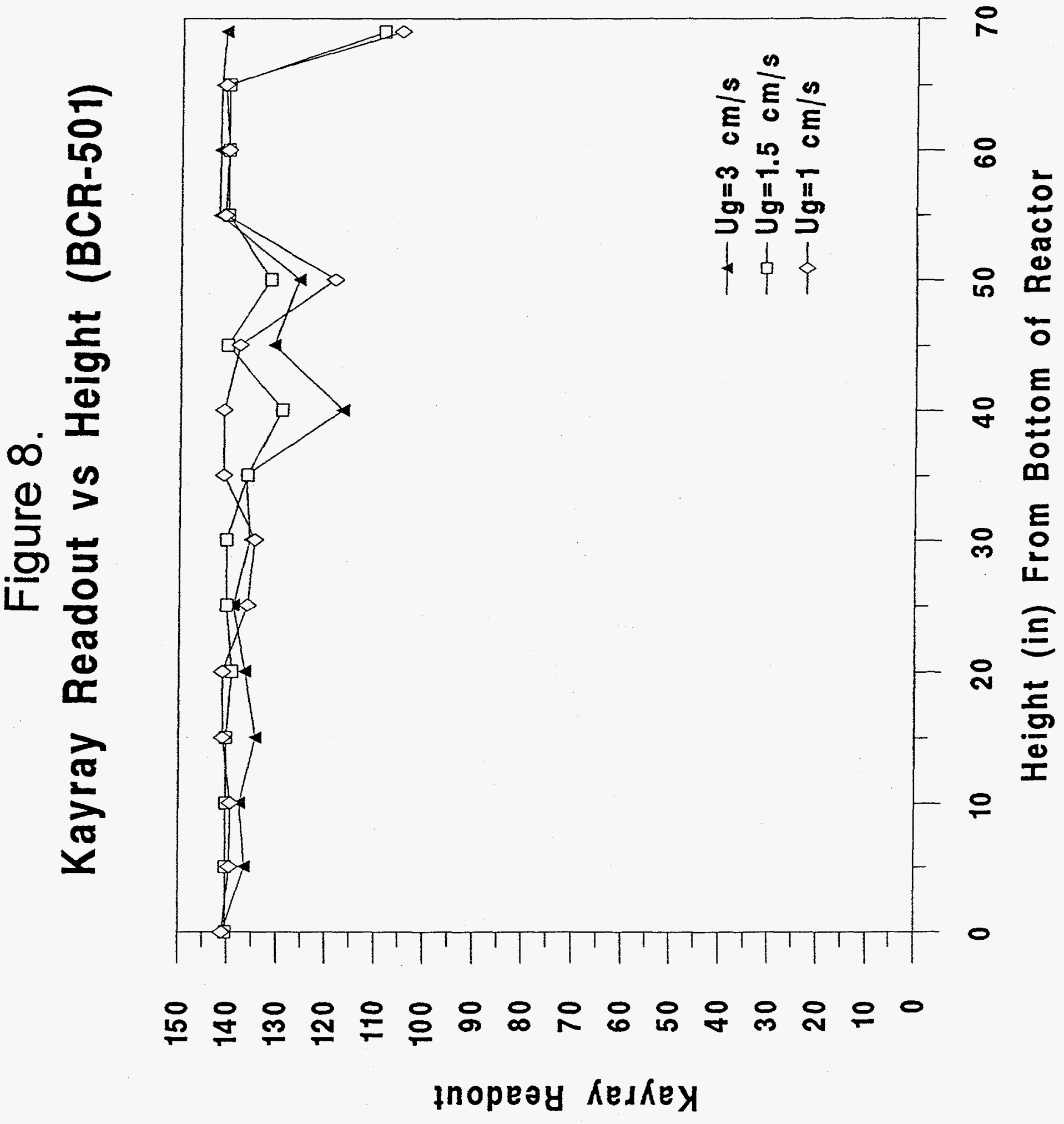


Figure 9.

Kayray Readout vs Height (BCR-501)

$\mathrm{Ug}=0 \mathrm{~cm} / \mathrm{sec}$.

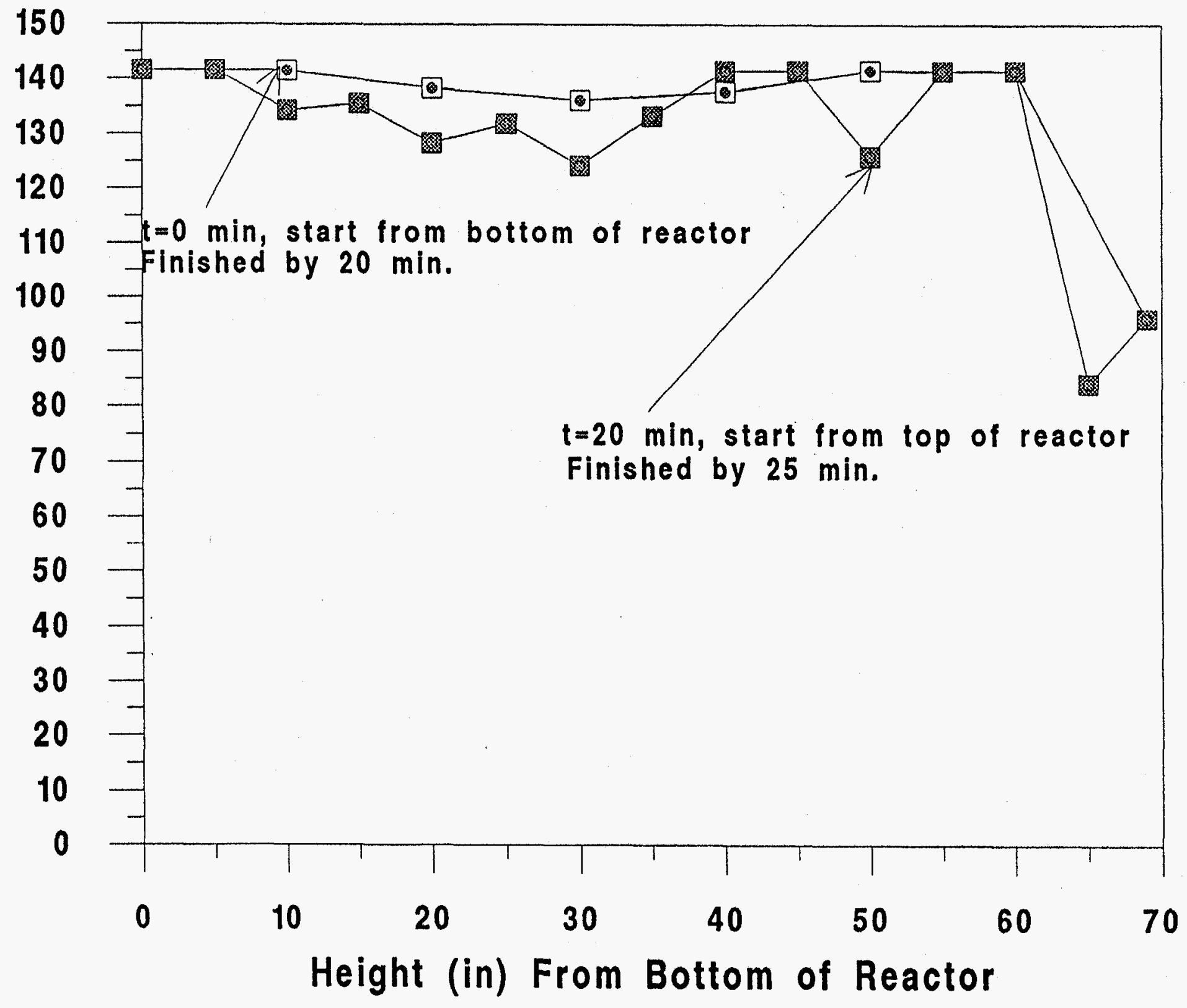

